\title{
ROVINJSKA TIPOGRAFIA ISTRIANA - KULTURNI MOMENT POVIJESTI
}

\author{
Igor Dobrača \\ Maistra d.d., Obala V. Nazora 6, Rovinj-Rovigno \\ idobraca@rovinj.net
}

\section{Sažetak}

Od otkrića, knjiga je oduvijek predstavljala medij prijenosa informacija i znanja. Izumom tiskarskog stroja 1450. godine započeto je novo poglavlje vrijednosti same knjige ali i otvaranje većeg broja tiskara. Braća Gaspare i Antonio Coana doselili su se početkom 1859. iz Venecije u Rovinj, tadašnji važan gospodarski centar, te 5. ožujka 1859. osnovali prvu tiskaru u Istri pod nazivom Tipografia Istriana. U radu je predstavljena djelatnost same tiskare Tipografia Istriana od njezina osnutka do transformacije u Istragrafiku u razdoblju nakon Drugog Svjetskog rata. Radom se želi dati akcenat na turističku valorizaciju tiskare i osvrt na izložbu otvorenu u Muzeju Grada Rovinja-Rovigno povodom 160. obljetnice njezina utemeljenja.

Ključne riječi: Tipografia Istriana, obitelj Coana, Rovinj-Rovigno, kulturna baština, turizam 


\section{Uvod}

Knjiga predstavlja jedan od izuzetno važnih izuma u povijesti čovječanstva s obzirom da je njezina pojava omogućila veću geografsku rasprostranjenost i jednostavnu dostupnost informacijama. Kinezi su tako prije nego što su izumili papir ${ }^{[1]}$ pisali na dugačkim i tankim trakama od bambusove trstike, na oklopu kornjače, na kosti, drvenim daščicama, kamenu, brončanim posudama, itd., a djela su umnožavali prepisivanjem, a uslijed nepouzdanosti prepisivača započeli su urezivati tekstove na javno dostupan kamen. Takav kamen se, osim udubljenja, premazao crnilom, pažljivo prislonio pisaći materijal i pritiskao kako bi crni otisak ostao na površini a slova bila bijele boje (Stipčević, 2006, 53-59). U doba Rimskog Carstva pisalo se na kori od drveta, lišću - posebice palminom, slonovoj kosti, staklu, pečenoj glini, povoštenim pločicama, kramici i papirusu. U grčko-rimskom svijetu papirus se smatra najvažniji pisaći materijal. Radio se od srčike podvodnog dijela močvarne biljke Cyperus papyrus $L$. koja je najviše rasla u delti rijeke Nil. Traka papirusa bila je širine od 25 do $30 \mathrm{~cm}$, a uobičajene dužine 6 do 10 metara, a tek iznimno 40 i više. Osim pisanja na papirusu koristio se i pergament za čiju se proizvodnju upotrebljavala koža sitne stoke. U navedenom dobu cijenjeni izdavači su brinuli o korektnosti prepisivanja, a naklade izdanja su pažljivo procjenjivane kako bi sve bilo rasprodano, na što je zasigurno utjecala skupoća izrade (Stipčević, 2006, 97-115). U srednjem vijeku pojavio se papir koji je prenesen iz arapskog svijeta i to najvjerojatnije od strane Jeana Montgolfiera koji je 1147. osnovao prvu tvornicu papira u Europi za kojeg se pretpostavlja da je umijeće izrade papira naučio tijekom zarobljeništva u arapskom svijetu. Prvi značajniji proizvođač papira postala je tvornica otvorena 1276. godine u Fabrianu, mjestu pored Ancone. Time je Italija postala najznačajniji proizvođač papira u Europi i istisnula arapske proizvođače (Stipčević, 2006, 221-224). U Europi se u srednjem vijeku javljaju ksilografske (drvorezne) knjige pretežito nabožnog sadržaja, a tek kasnije svjetovnog i praktičnog karaktera. Tek pojavom tiskarskog stroja Johannesa Gutenberga (Gensfleisch) 1450. godine koji uključuje slaganje metalnih slova kako bi se stvorio negativ teksta za umnožavanje te putem

[1] Stipčević navodi kako je papir izumio eunuh Tsai Lun 105. godine poslije Krista. 
preše tekst otisnuo na papir, započelo je novo razdoblje tiskarstva. Venecija od 1469. pa sve do kraja 15. stoljeća postaje glavno sjedište tiskara s preko 150 tiskarskih radionica (Stipčević, 2006, 341-375). Grof Charles Stanhope u razdoblju od 1800. do 1803. godine konstruirao je željeznu prešu (ranije su se koristile drvene) s većim površinama ploča, dok je Friedrich König 1812. godine konstruirao stroj pokretan na parni pogon. Uvođenje navedenih inovacija na polju tiskarstva nije bilo jednostavno, obzirom su određeni vodeći tiskari strahovali za rentabilnost svojih tiskara (Stipčević, 2006, 568-569).

\section{Dolazak obitelji Coana u Rovinj}

$\mathrm{U}$ navedenom turbulentnom razdoblju invencija u području tiskarstva, dva brata Gaspare i Antonio Coana doselili su se 1859. iz Venecije u Rovinj i pritom prenijeli svoju tiskaru. U dostupnim radovima nisu dani mogući razlozi doseljenja obitelji Coana, a obzirom na prethodno opisani povijesni kontekst, može se pretpostaviti kako upravo potaknuti neizvjesnošću za sudbinu tiskare i vlastitu egzistenciju odlučiše se na preseljenje. Treba također spomenuti i činjenicu kako veći gradovi u ostalom dijelu Hrvatske već imaju svoje tiskare, pa je moguće da je obitelj Coana nepostojanje tiskare na području Istre prepoznala kao potencijalno geografsko područje na kojem mogu pokrenuti tiskarsku djelatnost. 
Tablica 1. Pokretanje tiskara u nekim hrvatskim gradovima do kraja 19. stoljeća (Izvor: Hebrang Grgić, Ivana (2018). Kratka povijest knjižnica i nakladnika s kodovima i aplikacijom. Zagreb: Naklada Ljevak, str. 137)

\begin{tabular}{|c|c|c|c|c|c|}
\hline Godina & Grad & Tiskar / pokretač & Godina & Grad & Tiskar / pokretač \\
\hline ?? & Kosinj & & 1783. & Dubrovnik & $\begin{array}{l}\text { Carlo Antonio } \\
\text { Occhi }\end{array}$ \\
\hline 1494. & Senj & Blaž Baromić & 1787. & Dubrovnik & Andreas Trevisan \\
\hline 1530. & Rijeka & $\begin{array}{l}\text { Šimun Kožičić } \\
\text { Benja }\end{array}$ & 1790. & Karlovac & \\
\hline 1547. & Nedelišće & Juraj Zrinski & 1797. & Zadar & Domenico Fracasso \\
\hline 1586. & Varaždin & Hans Mannel & 1803. & Zadar & $\begin{array}{l}\text { Antonio Luiggi } \\
\text { Battara }\end{array}$ \\
\hline 1694. & Zagreb & $\begin{array}{l}\text { Pavao Ritter } \\
\text { Vitezović }\end{array}$ & 1809. & Karlovac & Gašpar Veisz \\
\hline 1742. & Osijek & Franjevačka tiskara & 1821. & Varaždin & Ivan Gjuro Sandilla \\
\hline 1766. & Zagreb & Antun Jandera & 1826. & Zagreb & Franjo Župan \\
\hline 1773. & Zagreb & $\begin{array}{l}\text { Johann Thomas } \\
\text { Trattner }\end{array}$ & 1835. & Zagreb & Ljudevit Gaj \\
\hline 1773. & Varaždin & $\begin{array}{l}\text { Johann Thomas } \\
\text { Trattner }\end{array}$ & 1866. & Vukovar & \\
\hline 1775. & Osijek & Ivan Martin Divald & 1890. & Krk & Dragutin Parčević \\
\hline
\end{tabular}

Tih godina na političkoj sceni vlada Alexander Bach, poznat po centralizaciji, germanizaciji i apsolutističkoj vladavini, te je tijekom njegova vladanja tiskovna politika bila pod strogom kontrolom. Postoje dokumentirani zapisi o pokušajima osnivanja tiskare u Istri 1848. godine sa svrhom tiskanja novina i časopisa za potrebe žitelja Istre, čiju je inicijativu pokrenuo Michelle Fachinetti, tadašnji istarski zastupnik u Carevinskome vijeću u Beču, no inicijativa nije realizirana (Bužleta, 2005, 210-211). 
Rovinj je tada sa svojih 11.000 stanovnika slovio za važan gospodarski centar s obzirom na ekonomsku tradiciju vezanu uz ribarstvo, poljoprivredu i eksploataciju mineralnih sirovina, ali i pojavu prvih manufaktura. Rovinj je također bio sjedište Istarske gospodarske komore i Okružnog suda, te imao Ured za pomorstvo i zdravstvo, Ured pošte i telegrafa i osnovnu školu. Pula je u to doba bila mali grad s 1.100 stanovnika a njezin procvat se vezuje uz imenovanje glavnom ratnom lukom Habsburške Monarhije.

Za razvoj tiskarstva važan utjecaj imalo je i uvođenje obaveznog školovanja djece 1869. godine. Prema dostupnim podacima popisa stanovništva iz 1880. godine Grad Rovinj je imao najmanje nepismenih, dok je prosjek u Istri bio $77,8 \%$.

Tablica 2. Stanje pismenosti u Rovinju 1880. godine (Izvor: Muzej Grada RovinjaRovigno)

\begin{tabular}{|l|l|l|}
\hline & Grad Rovinj & Općinski okrug Rovinj \\
\hline $\begin{array}{l}\text { broj } \\
\text { stanovnika }\end{array}$ & 9.522 & 4.417 \\
\hline čitaju i pišu & $42,9 \%$ od čega više žena & $\begin{array}{l}10,7 \% \text { od čega znatno više } \\
\text { muškaraca }\end{array}$ \\
\hline jedva čitaju & $2,3 \%$ od čega više žena & $3,6 \%$ od čega više žena \\
\hline $\begin{array}{l}\text { ni čitaju ni } \\
\text { pišu }\end{array}$ & $54,8 \%$ & $85,7 \%$ \\
\hline
\end{tabular}

Prema dostupnim anagrafskim podacima, Antonio Coana rođen je 15. lipnja 1823. u Veneciji od oca Giovannija Battiste i majke Antonije Andriola te kršten 22. lipnja iste godine u crkvi S. Giacomo dell'Orio, preminuo 10. ožujka 1884. godine. Oženio se 14. lipnja 1846. u Veneciji s Antonijom Tiepolo, od oca Domenica i majke Andreane Monti, rođene 24. kolovoza 1824. u Fratti, preminule 19. lipnja 1866. Imali su sina Gaetana, rođenog 28. lipnja 1853. u Veneciji. Po smrti supruge, Antonio se oženio za Margaritu Sbisà, s kojom je imao sina Antonija, rođenog 22. srpnja 1872, 
sina Giovan Battistu ${ }^{[2]}$ rođenog 20. kolovoza 1876. i kćerku Mariju Antoniju Pasqu rođenu 12. travnja 1868. (Budicin, 2011, 1,11).[3]

Tiskara je otvorena 5. ožujka 1859. godine pod nazivom Tipografia Istriana (Istarska tiskara), i kao što je bilo uobičajeno za navedeno razdoblje, uz tiskaru djelovale su knjižara i papirnica. Sjedište joj je bilo na tadašnjem Trgu Valdibora, danas Trg Garibaldi. Kao što i sam naziv kaže, bila je to prva moderna tiskara, a imala je i odobrenje za rad austrijske vlasti, koja je uspostavila svoju vladavinu u Istri 1814. godine (Izložba „Otisci utiska“ u Rovinju, 2018).

\section{Tiskarska djelatnost obitelji Coana}

Prva publikacija tiskare bilo je reizdanje povijesnog romana Origine delle feste veneziane (Podrijetlo venecijanskih festivala) objavljivane u seriji do 21 araka (Budicin, 2011, 2) ${ }^{[4]}$, iako noviji podaci ukazuju kako postoje i ranija izdanja (Proizvodi rovinjske tiskare. Izložba „Otisci utiska“, 2018). Jedna od prvih tiskanih knjiga o pulskoj areni izdana je 1860. godine pod nazivom L'anfiteatro di Pola (Pulska Arena), autora Giovannija Barsana. Od ostalih značajnijih djela treba spomenuti djelo Bernarda Benussija Saggio d'una geografia dell'Istria ad uso della studiosa gioventù (Esej o geografiji Istre za mlade), objavljenog 1874. godine, službene spise Istarskog sabora Atti della Dieta provinciale dell'Istria in Parenzo (Spisi Pokrajinskog sabora u Poreču) tiskane u razdoblju od 1863. do 1876. godine, djelo nepoznatog autora pod nazivom Intorno la vita, il martirio ed il culto della vergine Calcedonese Santa Eufemia della quale il sacro corpo si conserva e si venera nella insigne Collegiata di Rovigno (Istria) (O životu, mučeništvu i kultu kalcedonske djevice svete Eufemije od kojih je sveto tijelo sačuvano i štovano u uglednoj rovinjskoj crkvi) posvećena životu sv. Eufemije, zaštitnici grada Rovinja, tiskana 1891. godine (Bužleta, 2005, 209). Kao što se može i pretpostaviti tiskara je djelovala na tržišnim principima a pripremana su izdanja za koja se pretpostavljalo da će biti

[2] Giovan Battista preminuo je 11. rujna 1877.

[3] Rad je predstavljen na znanstvenom skupu „150 godina od uspostave Istarskog pokrajinskog sabora u Poreču / A 150 anni dalla costituzione della Dieta istriana provinciale a Parenzo" održanom u Poreču od 13. do 15. listopada 2011.

[4] Prvo izdanje u više svezaka izašlo je u Veneciji u razdoblju od 1817. do 1827. godine u tiskari Alvisopoli. 
dobro prihvaćena i samim time komercijalno isplativa, što su uglavnom činile knjige vjerskog sadržaja i kalendari. Prema narudžbi tiskali su „plakate, novine, razne pravne akte, raznolike materijale i obrasce za lokalnu, regionalnu i državnu upravu, obrtnike i trgovce, prigodna izdanja povodom završetka školovanja, vjenčanja... Ta [...] je djelatnost, uz prodaju uredskog i školskog pribora, bila najveći izvor prihoda“. Osim toga izrađivali su stolne i džepne kalendare, džepne rokovnike, bilježnice za osnovnu školu, kajdanke, memorandume, pečate, posjetnice, osmrtnice i slično. U pogledu očuvanja dijalekta, tiskaju brošuru napisanu na rovinjskom dijalektu autora Piera Angelinija I lementi de Fimjta incontro Piro su murus e Due anni despoi el Matrimogno (Jadikovke Fume kada je pronašla svog ljubljenog Peru i dvije godine nakon vjenčanja) (Budicin, 2011, 16).

Ustavom iz 1860. liberalnije je uređeno područje tiskarstva, no naravno time nije ukinut nadzor nad tiskarskom djelatnošću. Dotadašnji propisi vezani uz tisak propisivali su mnoga ograničenja: poticanje na razdor države, pobunu ili građanski rat; uvredu ustava; poticanje na neprijateljstvo među narodnostima, vjerama, klasama i korporacijama; napad na nepovredivost vladara; pozivanje na nepoštivanje zakona, naredbi ili sudskih odluka, širenje glasina ili pornografije; uvrede časti ili objava informacija iz privatnog života; uvrede pokojnika, ... (Pastović, 2015, 4748). U navedenom razdoblju novine u Istri su zapravo bili glasnici politike, kada su i jačali nacionalni pokreti i liberalne ideje. Rovinj tada postaje sjedište talijanskog liberalno-nacionalnog pokreta koji upravo u novinama prepoznaje značajan potencijal za djelovanje političke propagande. U novinama se tako objavljuju tekstovi, bilo u direktnom ili ironičnom stilu, u vidu stavova usmjerenih protiv države, klera, socijalista,... Stoga izdanja bivaju često cenzurirana ili sekvestrirana, bilo već u samim tiskarama ili pak primjerice u kavanama. (Novine i plakati. Izložba „Otisci utiska“, 2018).

Obzirom na važnost novina u navedenom razdoblju, tiskara od 15. veljače 1860. započinje tiskati prvi lokalno-regionalni tjednik L'Istriano (Istranin) koji je izlazio na osam stranica na kojima je tekst bio raspoređen u dva stupca ${ }^{[5]}$. Tjednik se bavio temama iz područja književnosti, znanosti,

[5] Smatra se kako je tiskara Coana radila na tržišnim principima, te je tiskala novine različitih političkih opcija. 
umjetnosti, trgovine i poljoprivrede, a uređivao ga je Federico Spongia, ljekarnik. Obzirom je za suradnike imao i osobe (Tomaso Luciani, Nazario Gallo, Antonio Madonizza, Giovanni i Luigi Barsan, Angelo Menegazzi, Carlo Combi, Carlo De Franceschi, Giovan Battista Cipriani) koje su tjedniku davali i političku konotaciju, tjednik je znao biti cenzuriran ili zaplijenjen. Tiskara je cenzurirane dijelove teksta novina ostavljala praznima uz poruku Censurato (Cenzurirano), čime je zapravo ostao jasno vidljiv trag utjecaja cenzora nad novinskom djelatnošću. Tjednik je prestao izlaziti 31. srpnja 1861.

Dvomjesečnik Il Maestro del Popolo (Narodni učitelj) izlazi 5. travnja 1874. a bavi se kršćanskim i očinskim temama lokalnih pedagoškoedukacijskih okvira, koji je međutim izlazio tek do 10. siječnja 1875. Samo tijekom 1875. godine izlazio je časopis Effemeride agraria dell'Istria (Poljoprivredni efemerid Istre) koji je uređivao Nicolò Sbisà a izdavala Società agraria istriana (Poljoprivredna udruga Istre).

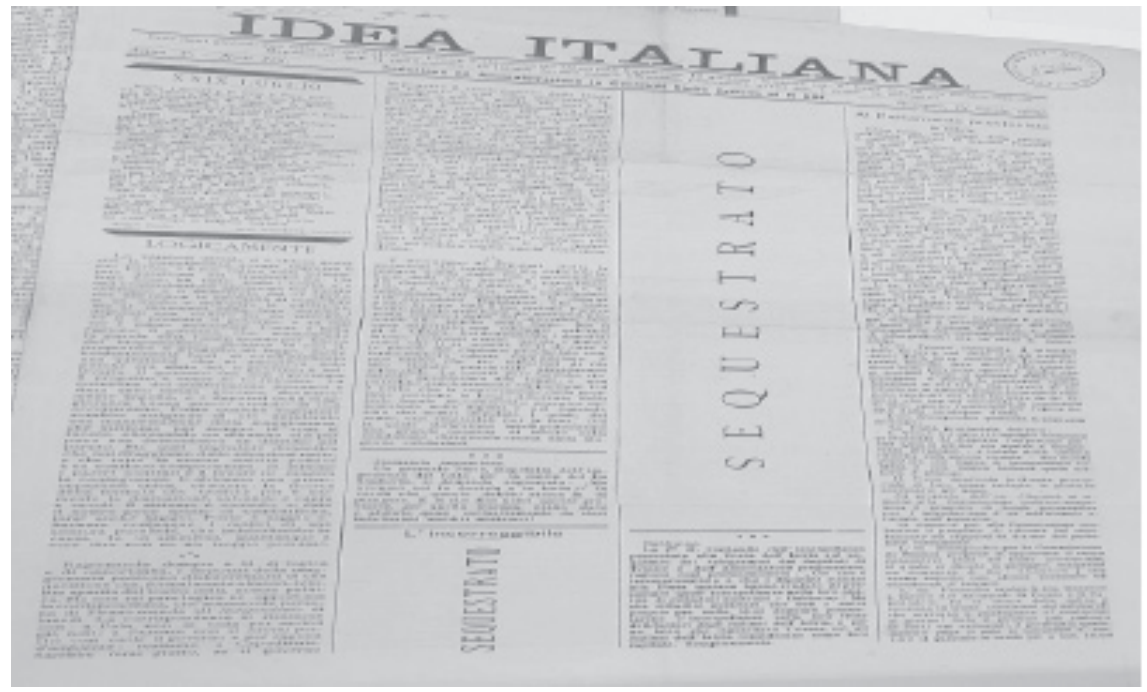

Slika 2. Primjer cenzure u časopisu Idea italiana (Izvor: Muzej Grada RovinjaRovigno)

Tiskara koja je tada promijenila ime u Stabilimento tipografico - Cartoleria e Legatoria Antonio Coana (Tiskara - knjižara i uvezivanje Antonio Coana) 4. travnja 1904. godine, smrću Antonija Coane (sina), 
prelazi u vlasništvo maloljetne Margherite. ${ }^{[6]}$ Vraća joj se naziv Tipografia Coana (Tiskara Coana), a tiskarom upravlja Carolina De Costantini, udovica Antonija Coane, i njezin šogor Giuseppe Bartoli, aktivan član u rovinjskom društveno-političkom životu (Budicin, 2011, 11). Od 1936. tiskara mijenja vlasnika i postaje Tipografia Antonio Gerini (Tiskara Antonio Gerini) te djeluje sve do 1947., nakon čega je s njezinim strojevima pokrenuta Tipografia cittadina (Gradska tiskara), a 1. svibnja 1956. s istim strojevima osnovana je Istragrafika (Istrapedia. Coana, 2019). Navedena promjena dogodila se nacionalizacijom imovine te tiskara nastavlja $\mathrm{s}$ djelovanjem kao narodno dobro. Do 1966. tiskale su se slikovnice za djecu i turistički promidžbeni materijali. Nova transformacija događa se 1974. godine osnivanjem Osnovne organizacije udruženog rada "Istragrafika“ u sastavu Tvornice duhana i ambalaže kada se prestaje s knjigotiskom a posvećuje ambalaži (Od Tipografia Istriana do Istragrafike. Izložba „Otisci utiska“., 2018.).

U Muzeju Grada Rovinja-Rovigno čuva se okvir tiskarske preše, proizvođača Loeser, iz Beča iz 1870. godine. Na njoj se nalazio i natpis Presse Freiheit (Sloboda tisku) vezan uz ukidanje cenzure i proglašenje slobode tiska koja se dogodila 1848. godine odlukom austrijskog cara Ferdinanda. Nakon Drugog svjetskog rata korištena je u Istragrafici za izradu plakata i probnih otisaka, a donesena je u muzej 1976. godine povodom izložbe u čast 20. godina Istragrafike. Nažalost, zbog loših uvjeta čuvanja korodirala je i zagubljeni su dijelovi mehanizama, te je radi očuvanja restaurirana 2017. godine u Muzeju za umjetnost i obrt u Zagrebu i čuva se u Muzeju Grada Rovinja-Rovigno (Od Tipografia Istriana do Istragrafike. Izložba „Otisci utiska“., 2018.).

\section{Turistička valorizacija tiskare Coana}

S kulturnog aspekta turistima je u svakoj destinaciji gdje borave interesantno pogledati i saznati nešto o gradu u kojem su odsjeli. Istraživanje iz 90 -tih godina prošlog stoljeća u pogledu vrijednosnih elemenata pri planiranju putovanja (Silberberg, 1995, 363-364) ukazala su

[6] Gaetano Coana, sin iz prvog braka, 1876. godine preselio se u Poreč gdje je također otvorio tiskaru opremljenu starijim tiskarskim strojevima rovinjske tiskare. 
na povećan interes turista za kulturne, povijesne i arheološke znamenitosti gdje je postotak ispitanika s $27 \%$ u istraživanju provedenom 80 -tih povećalo se na 50\% u 90-tima, dok element razumijevanja kulture destinacije povećan je s $48 \%$ a $88 \%$. Prema aktualnijim podacima, kulturni turizam u stalnom je porastu te tako za 2017. godinu procijenjeno je kako on čini viši od 39\% međunarodnih turističkih putovanja (Richards, 2018, 13), što ukazuje na kontinuiranu potrebu promišljanja o integraciji kulturnih elemenata u ponudu turističke destinacije.

Vrijednu informaciju o postojanju tiskare obitelji Coana u svoju brošuru „Kulturno povijesni itinerari“ uvrstila je i lokalna Turistička zajednica grada Rovinja, gdje samo ukratko navodi informaciju o postojanju tiskare: „Tik do tržnice nalazi se gradska ribarnica renovirana 2004. godine, s ulazom i sa strane Trga G. Garibaldija. U tom je prostoru do 1947. godine poslovala rovinjska tiskara, otvorena 1859. kao Prima tipografia istriana, pa Tipografia Coana te naposljetku Gradska tiskara“ (Budicin, 2016, 26).

Izložba „Otisci utiska. Odjeci modernog tiskarstva u Rovinju i Poreču (1859. - 1974.)“ otvorena je u Muzeju Grada Rovinja-Rovigno 21. prosinca 2018. godine. Postav izložbe kronološki prikazuje nastanak, razvoj, djelovanje i proizvode tiskare koju je 1859. utemeljio Antonio Coana. Izložbom se željela i istaknuti uloga rovinjske tiskare u javnom i privatnom životu građana Istre, te predstaviti Rovinj kao izvorište razvoja tiskarstva u Istri obzirom su znanja, vještine i oprema rovinjske tiskare doprinijeli otvaranju tiskara u Puli i Poreču ${ }^{[7]}$. Važno je navesti kako je izložba realizirana također uz pomoć pojedinaca koji su posudili građu ili su temeljem svojeg zaposlenja u grafičkoj industriji pružili određena saznanja, čime se zapravo prepoznala ali i ističe važnost pojedinaca u usmenoj povijesti i potreba zapisivanja iste čime se osigurava dokumentiranje povijesti za buduće generacije i istraživački rad. Usmenom poviješću prikupljaju se i trajno pohranjuju iskustva i povijest, bilo individualna, ili pak grupna s ciljem očuvanja tradicijske povijesti zajednice, a sve kako bi se što vjernije moglo pristupiti razumijevanju i proučavanju prošlosti. U muzejima se primjerice kazivači usmene povijesti snimaju nakon čega se prikupljeni podaci dokumentiraju i pohranjuju za potrebe budućih

[7] Tiskaru u Puli otvorio je 1869. godine bivši zaposlenik rovinjske tiskare, dok tiskaru u Poreču otvorio je 1875. godine Gaetano Coana, Antonijev sin iz prvog braka. 
korisnika ili istraživanja (Orlić, 2006, 153).

Novi iskorak u kulturno-turističkoj valorizaciji tiskare dogodio se 5. ožujka 2019. gdje su na ulazima u prostor tadašnje tiskare postavljene spomen-ploče na hrvatskom, talijanskom i engleskom jeziku. Tom prigodom rovinjski dogradonačelnik Marino Budicin izjavio je kako „obitelj Coana sa svojom tiskarom uvelike je pridonijela razvoju ne samo kulture već i škole jer je tiskala školske publikacije. Tiskara je imala veliki značaj u promoviranju novinskih publikacija, a uloga obitelji Coana zaista se osjetila" (Na oba ulaza u ribarnicu postavljene spomen-ploče: Rovinjska tiskara "Tipografia Istriana" imala je veliki značaj., 2019).

Prema planu Općih javnih potreba u kulturi za 2019. godinu u planu je digitalizacija knjiga tiskanih u tiskari Coana čime se stvaraju preduvjeti za daljnju kulturno-turističku valorizaciju i potencijalni razvoj novih turističkih proizvoda i usluga, ali i omogućuje veću dostupnost građe istraživačima i ostalim zainteresiranim osobama, te očuva izvornike od uništenja (Grad Rovinj. Opće javne potrebe u kulturi, 2019).

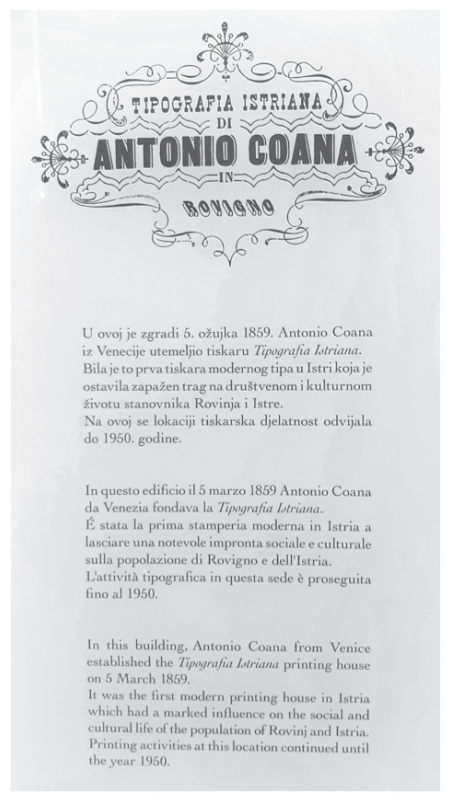

Slika 3. Spomen ploča (Foto: autor) 


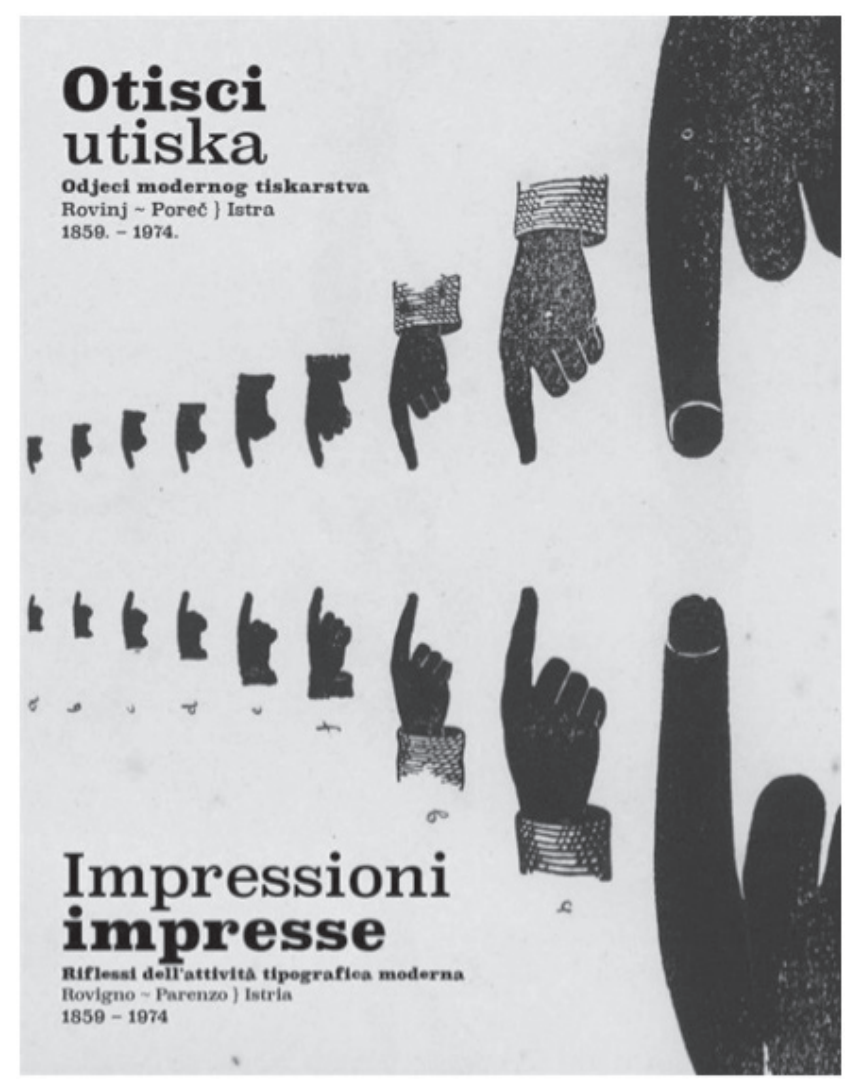

Slika 4. Plakat izložbe "Otisci utiska” 


\section{Zaključak}

Tiskara Coana s povijesnog aspekta ima značajnu ulogu u razvoju tiskarstva u Istri, obzirom na njezin primat u navedenoj djelatnosti. Također je potrebno istaknuti kako su njezina izdanja imala i značajan utjecaj na stjecanje novih znanja i spoznaja, obzirom na široku lepezu knjiga, novina, tjednika, mjesečnika, kalendara i ostalog tiskanog materijala koji su izdavali. Ne treba zaboraviti kako je upravo ta mala obiteljska tiskara svojom pojavom u 19. stoljeću služila i kao rasadnik kompetencija za otvaranje ostalih tiskara u Poreču i Puli. Kroz vrijeme, nacionalizacijom nakon Drugog svjetskog rata transformirana je u Istragrafiku.

Zadnjih godina u Rovinju je prepoznata kulturna i turistička vrijednost nekadašnje tiskare, te je pokrenut niz inicijativa, od podsjećanja na činjenicu kako se radi o prvoj tiskari u Istri, postavljanja izložbe s iscrpnim i bogatim postavom u Muzeju Grada Rovinja-Rovigno, postavljanje spomen-ploče, do najave digitalizacije tiskane građe. Navedene inicijative osiguravaju, osim građanima i turističkom sektoru, svakako i istraživačima mogućnost daljnjeg proučavanja djelovanja tiskare i njezinog utjecaja na razvoj Istre u tiskarskom i nakladničkom smislu, te posljedično upravnom i obrazovnom razvoju. 


\section{Literatura}

Budicin, Marino (13.-15. listopada 2011.). Le tipografie rovignese e parentina dei Coana nei risvolti della loro attività tipografica nella stampa e pubblicazione di giornali, libri, volumi e opuscoli vari (1859-1914). [Relazione a convegno]. „150 godina od uspostave Istarskog pokrajinskog sabora u Poreču / A 150 anni dalla costituzione della Dieta istriana provinciale a Parenzo“, Poreč.

Budicin, Marino (2016). Kulturno povijesni itinerari. Rovinj: Turistička zajednica grada Rovinja-Rovigno.

Bužleta, Nadia (2005). Tiskarstvo i nakladništvo u Istri 1859.-1941. Vjesnik bibliotekara Hrvatske, 48(3/4), 208-232.

Glas Istre (9. ožujka 2019). Na oba ulaza u ribarnicu postavljene spomenploče: Rovinjska tiskara "Tipografia Istriana" imala je veliki značaj. Izvor: https://www.glasistre.hr/pula/na-oba-ulaza-u-ribarnicu-postavljenespomen-ploce-rovinjska-tiskara-tipografia-istriana-imala-je-velikiznacaj-582874 (pregledano 6. srpnja 2019.)

Glas Istre (21. prosinca 2018). O povijesti tiskarske djelatnosti u Istri u Muzeju grada Rovinja: Otisci utiska - o odjecima modernog tiskarstva. Izvor: https://www.glasistre.hr/pula/o-povijesti-tiskarske-djelatnostiu-istri-u-muzeju-grada-rovinja-otisci-utiska-o-odjecima-modernogtiskarstva-577375 (pregledano 9. travnja 2020.)

Grad Rovinj-Rovigno (n.d.). Opće javne potrebe u kulturi. Izvor: https:// www.rovinj-rovigno.hr/kultura-znanost-i-sport/kultura-u-rovinju/javnepotrebe/ (pregledano 6. srpnja 2019.)

Hebrang Grgić, Ivana (2018). Kratka povijest knjižnica i nakladnika s kodovima i aplikacijom. Zagreb: Naklada Ljevak.

Istrapedia - istarska internetska enciklopedija (15. ožujka 2019). Coana. Izvor: https://www.istrapedia.hr/hrv/511/coana/istra-a-z/ (pregledano 6. srpnja 2019.)

Izložba „Otisci utisaka“ u Rovinju (n.d.). Pula: Regional express, 20.12.2018. Izvor: http://www.regionalexpress.hr/site/more/izlozhba-otisci-utisaka-u- 
rovinju (pregledano 6. srpnja 2019.)

Muzej Grada Rovinja-Rovigno (2018). Izložba „Otisci utiska. Odjeci modernog tiskarstva u Rovinju i Poreču (1859. - 1974.)“ Rovinj : Muzej Grada Rovinja-Rovigno.

Orlić, Olga. Kako metodu usmene povijesti / oral history uklopiti u muzejsku izložbu? Etnološka tribina : Godišnjak Hrvatskog etnološkog društva, 36(29), 151-159.

Pastović, Dunja (2015.) Sloboda tiska i porotna sudbenost u Istri 1848./1849. Zbornik Pravnog fakulteta Sveučilišta u Rijeci, 36(2), 725-758.

Richards, Greg (2018.) Cultural tourism: A review of recent research and trends. Journal of Hospitality and Tourism Management, 36, 12-21.

Silberberg, Ted (1995). Cultural tourism and business opportunities for museums and heritage sites. Tourism Management, 16(5), 361-365.

Stipčević, Aleksandar (2006). Povijest knjige. Zagreb : Matica hrvatska.

\section{Summary}

Since its discovery, the book has always been the medium of information and knowledge transfer. With the invention of the printing press in 1450, a book itself acquired new value while printing houses spread widely. The brothers Gaspare and Antonio Coana immigrated from Venice to Rovinj in 1859, then an important economic centre, and on March 5, 1859, established the first printing house in Istria called Tipografia Istriana. The aim of paper is to present the activity of the printing house Tipografia Istriana from its foundation to the transformation into Istragrafika that took place in the period after the World War II. The paper also seeks to emphasize the tourist valorisation of the printing house and give an overview of the exhibition opened on the occasion of the 160th anniversary of its founding in the Rovinj-Rovigno City Museum.

Keywords: Tipografia Istriana, Coana family, Rovinj-Rovigno, cultural heritage, tourism 
